\title{
BLENDS OF POLY(METHYL METHACRYLATE-CO-METHACRYLIC ACID) AND TWO DIHYDRIC PHENOLS: THERMAL AND INFRARED SPECTROSCOPIC STUDIES
}

\author{
NICOLÁS GATICA*, NANCY ALVARADO AND DANIELA SEPÚLVEDA
}

Facultad de Ciencias Químicas, Universidad de Concepción, Concepción, Chile.

\begin{abstract}
The miscibility in blends containing poly(methyl methacrylate-co-methacrylic acid) [P(MMA-co-MA)] as polymer component and the dihydric phenols 4,4'-thiodiphenol (TDP) and 4,4'-methyllendiphenol (MDP) as low molecular weight compounds (LMWC) was studied by Differential Scanning Calorimetry (DSC) and Fourier Transform Infrared Spectrophotometry (FTIR). Thermal properties, such as the glass transition of P(MMA-co-MA) and the melting of the LMWC, were found to be clearly affected when the compounds were blended, which was attributed to the miscibility between them. FTIR was used to investigate the specific interactions between P(MMA-co-MA) and the LMWC. The formation of intermolecular hydrogen bonds between the carbonyl groups of P(MMAco-MA) and the hydroxyl groups of TDP and MDP were discovered. Thermogravimetric and viscometry analysis were also used as additional techniques to complement the obtained FTIR and DCS results.
\end{abstract}

Keywords: blends, poly(methyl methacrylate-co-methacrylic), 4,4'-thiodiphenol, 4,4'-methyllendiphenol, hydrogen bond, low molecular weight compounds.

\section{INTRODUCTION}

The blending of two materials to obtain a balance of properties has been worked successfully in the metallurgical field. The appropriate combination of two or more different polymer structures to get a new polymeric material with the properties of their components is not a new idea. In this sense, the necessity to find polymer materials with new and specific applications has driven polymer blending to become one of the most important research subjects, both academically and industrially (1-7).

Even if a considerable number of problems remains unsolved in the interpolymer miscibility area, some fundamental bases have been established, such as the importance of the specific interactions (hydrogen bonding, dipolar, charge transference interactions and other) between the components. For macromolecules, the blending Gibbs free energy $\left(\Delta \mathrm{G}^{\mathrm{M}}\right)$ is controlled by its enthalpic contribution $\left(\Delta \mathrm{H}^{\mathrm{M}}\right)$ due to the entropic factor $\left(\Delta \mathrm{S}^{\mathrm{M}}\right)$ is normally unfavorable because of the high molecular weight of the blend components. Thus, polymer pairs with complementary chemical functions lead to miscible systems. There is much information in the literature indicating that compatible polymer blends were obtained through functionalized macromolecular systems. This information includes a wide variety of components such as addition and condensation homo and copolymers (2-20). The common factor in this kind of studies is the presence of different chemical functions in the macromolecule in order to counteract the unfavorable entropic factor mentioned above. Therefore, from this general behavior, it would be interesting to study the properties of polymeric materials blended with low molecular weight compounds (LMWC), which can potentially modify and ideally improve the properties of the macromolecular component if one considers that the unfavorable entropic factor of the polymer1-polymer2 systems is practically negligible in polymer-LMWC blends. Moreover, the analysis of this kind of blends would be interesting not only from the fundamental perspective, but these systems can also be an alternative way to recycle preexistent polymeric materials, finding new applications after modifying and improving macroscopic properties such as mechanical properties (resistance, elongation and hardness), processability and flexibility and thermal an thermogravimetric properties (glass transition and fusion temperatures and thermal decomposition) $(21,22)$.

In comparison with polymer-polymer blends, there are few studies on the characterization of polymer-LMWC blends. One instance is the controlled releasing of drugs from polymer matrixes (23-27). In any case, this kind of studies has an important but specific and delimited objective. There are no systematic studies on blends of addition polymers with LMWC, and only some articles about condensation polymers as the polymeric component have been reported. Inoue et al. have described the characterization of poly $(\varepsilon-$ caprolactone) blended with some LMWC such as dihydric phenols and amino compounds $(21,22,28,29)$.

A large number of works described in literature on polymer-polymer compatibility includes poly(4-vinylphenol) (P4VPh) and copolymers containing the 4-vinyl phenol (4VPh) unit as blend components because of the 4VPh's particular chemical structure, which promotes miscibility with many polymers pairs $(2,9,13,30-33)$. $\mathrm{P} 4 \mathrm{VPh}$ is an efficient proton-donor polymer that easily generates hydrogen bonding because of the good spatial disposition of the hydroxyl group in the para position of the aromatic ring. This characteristic suggests that some dihydric phenols, such as $4,4^{\prime}$-methylenediphenol (MDP) and 4,4'-thiodiphenol (TDP), can be considered as potentially interacting LMWC, whose structural formulae are presented in Figure 1.

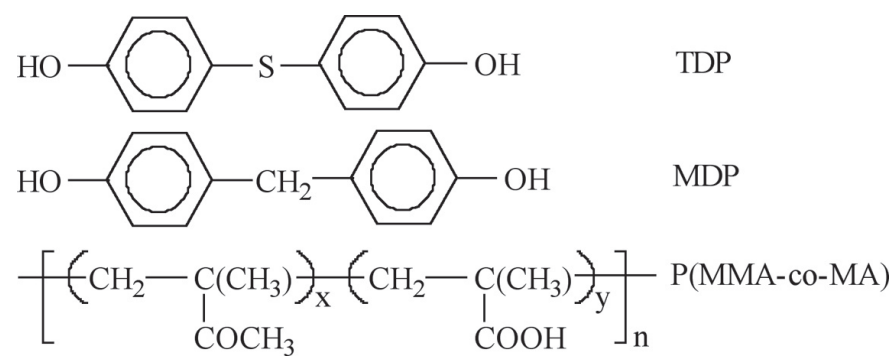

Figure 1. Structural Formulae of 4,4'-thiodiphenol (TDP), 4,4'methylenediphenol (MDP) and poly(methyl methacrylate-co-methacrylic acid) [P(MMA-co-MA)].

The eventual interaction capability of this kind of LMWC would promote a significant association with different kind of macromolecules, originating a type of physical bulky side group, which would remarkably modify properties such as mechanical, thermal and thermogravimetric properties mentioned above. Furthermore, the bifunctionality of molecules like MDP and TDP could also promote a physical crosslinking effect between potentially interacting macromolecular chains. Functionalized polymers should be used to achieve this, according to a series of studies, whose reports include, but are not limited to polymers containing vinyl pyridines $(4,11,34), \mathrm{N}$-vinyl pyrrolidone $(4,13,34)$, vinyl phenol $(2,9,13,30-33)$ and methacrylate $(5,11,34)$ units. Poly(methyl methacrylate-co-methacrylic acid) [P(MMA-co-MA)] (Figure 1) is a well known functionalized vinyl copolymer previously used in polymer blends $(35,36)$ and that presents interesting structural properties as the presence of polar and proton-donor groups that can be considered as potentially interacting units.

The aim of this work is to study the compatibility of polymer - LMWC blends to identify the effect of specific interactions on the miscibility. To do this, blends of P(MMA-co-MA) with TDP (blend A) and MDP (blend B) were studied by Differential Scanning Calorimetry (DSC), Fourier Transform Infrared Spectrophotometry (FTIR), Thermogravimetric Analysis (TGA) and viscometry. 


\section{EXPERIMENTAL}

\section{Blend components}

Aldrich's P(MMA-co-MA), TDP and MDP were used. The weightaverage molecular weight $\left(\mathrm{M}_{\mathrm{w}}\right)$, the glass transition temperature $(\mathrm{Tg})$ and the methyl methacrylate to methacrylic acid molar ratio of P(MMA-co-MA) are $15,000 \mathrm{~g} / \mathrm{mol}, 107.9^{\circ} \mathrm{C}$ and 1:0.016 respectively. Melting points of TDP and MDP are $152.8^{\circ} \mathrm{C}$ and $163.8^{\circ} \mathrm{C}$ respectively. $\mathrm{M}_{w}$ and copolymer composition correspond to the supplying's values and $\mathrm{Tg}$ and $\mathrm{Tm}$ were determined by DSC.

\section{Preparation of blends}

Blends of different compositions were prepared by solution casting, using tetrahydrofuran as solvent. Then, they were evaporated at room temperature and vacuum dried at $308 \mathrm{~K}$ for $1-2$ weeks until constant weight. The blend concentration was about $2 \mathrm{w} / \mathrm{w} \%$.

\section{Viscometry measurements}

Intrinsic viscosity $([\eta])$ of P(MMA-co-MA) and the different blends was determined using a Ostwald-type capillary dilution viscometer in tetrahydrofuran at $298 \mathrm{~K}$ without kinetic energy corrections. Intrinsic viscosities were obtained using the Solomon Gotessman equation (37).

\section{FTIR spectra}

Infrared spectra of P(MMA-co-MA), LMWC and their blends were recorded on a Nicolet Magna IR 550 Fourier transform infrared spectrophotometer. Spectra were recorded with a resolution of $1 \mathrm{~cm}^{-1}$. Samples were prepared directly in $\mathrm{KBr}$ pellets.

\section{DSC measurements}

The glass transition temperature (Tg) of P(MMA-co-MA) and blends and the melting temperatures (Tm) of TDP, MDP and blends were measured by Differential Scanning Calorimetry (DSC) from the thermograms obtained with a Differential Scanning Calorimeter Rheometric Scientific DSC Plus, with the Orchestrator program as graphical software. Samples (3-4 mg) were placed inside aluminium pans and heated under flowing nitrogen $(25 \mathrm{~mL} / \mathrm{min})$, ranging from 25 to $200{ }^{\circ} \mathrm{C}$, at $10\left({ }^{\circ} \mathrm{C} / \mathrm{min}\right)$.

To minimize differences in the samples' thermal history, $\mathrm{Tg}$ and $\mathrm{Tm}$ determination was performed as follows: heating until the final temperature (dynamic stage), isothermal stage at the final temperature (static), cooling until the initial temperature (dynamic, quenching step), isothermal step at the initial temperature (static) and heating until the final temperature (dynamic). In all cases, the $\mathrm{Tg}$ was evaluated from the last stage.

Samples were dried under reduced pressure in a vacuum oven prior to measurement.

\section{TGA measurements}

Thermogravimetric measurements were performed using a thermal analyzer TGA Polymer Laboratories STA 625. Samples (2-3 mg) were placed inside aluminium pans and heated under flowing nitrogen $(41 \mathrm{~mL} / \mathrm{min})$ ranging from 25 to $550{ }^{\circ} \mathrm{C}$, at $10^{\circ} \mathrm{C} / \mathrm{min}$, obtaining the corresponding thermal decomposition profiles.

Samples were dried under reduced pressure in a vacuum oven prior to measurements.

\section{RESULTS AND DISCUSSION}

Table 1 lists the blending composition of the two series studied (blends $\mathrm{A}$ and $\mathrm{B}$ ) and other properties determined as the intrinsic viscosity and the $\mathrm{T}_{50}$ values obtained from thermogravimetric analysis. Figure 2 shows the DSC thermograms corresponding to the $\mathrm{A} 1-\mathrm{A} 7$ and $\mathrm{B} 1-\mathrm{B} 7$ series, recorded during the second heating scan. P(MMA-co-MA) (A1) shows a very clear Tg value at $107.9^{\circ} \mathrm{C}$ (supplier reference value $105^{\circ} \mathrm{C}$ ), which disappears when the content of TDP increases, from A2 to A6. This is a interesting result because even if it is difficult to attribute this behavior to miscibility between the components, if phase separation takes place, the $\mathrm{Tg}$ value corresponding to the pure copolymer should be clearly detected as observed for the A1 sample.
Table 1. Blending compositions and their corresponding denomination, intrinsic viscosity $([\eta])$ and $\mathrm{T}_{50}$ values for the studied blends.

\begin{tabular}{|c|c|c|c|c|c|c|}
\hline $\begin{array}{c}\text { B 1 e n d } \\
\text { composition } \\
\left(\begin{array}{c}\text { (weight \% of } \\
\text { LMWC) }\end{array}\right.\end{array}$ & $\begin{array}{c}\text { DMWC }= \\
\text { TDP }\end{array}$ & $\begin{array}{r}\text { LMWC } \\
=\text { MDP }\end{array}$ & $\begin{array}{c}\text { LMWC }= \\
\text { TDP }\end{array}$ & $\begin{array}{r}\text { LMWC }= \\
\text { MDP }\end{array}$ & $\begin{array}{c}\text { LMWC }= \\
\text { TDP }\end{array}$ & $\begin{array}{c}\text { LMWC }= \\
\text { MDP }\end{array}$ \\
\hline 0 & A1 & B1 & 0.26 & 0.26 & 389 & 389 \\
\hline 20 & A2 & B2 & 0.24 & 0.24 & 381 & 395 \\
\hline 40 & A3 & B3 & 0.18 & 0.18 & 370 & 385 \\
\hline 50 & A4 & B4 & 0.23 & 0.21 & 362 & 362 \\
\hline 60 & A5 & B5 & 0.20 & 0.15 & 330 & 314 \\
\hline 80 & A6 & B6 & 0.20 & 0.18 & 294 & 298 \\
\hline 100 & A7 & B7 & - & - & 302 & 281 \\
\hline
\end{tabular}

(*) Tetrahydrofuran, $25^{\circ} \mathrm{C}$.

The glass transition represents an abrupt change in the mobility of the chain segments of a macromolecule in the amorphous phase. The temperature at which this transition occurs (Tg) is very affected by little local modifications (38). In this case, the molecules of TDP might act as a physical bulk side group of the P(MMA-co-MA) chain in the blend, as a consequence of some kind of intermolecular interaction. Furthermore, TDP should also act as a physical crosslinking agent in the blend. Consequently, the disappearing of the glass transition temperature can be interpreted in terms of a loss of the molecular mobility of the copolymers chains when they interact with the TDP ones.
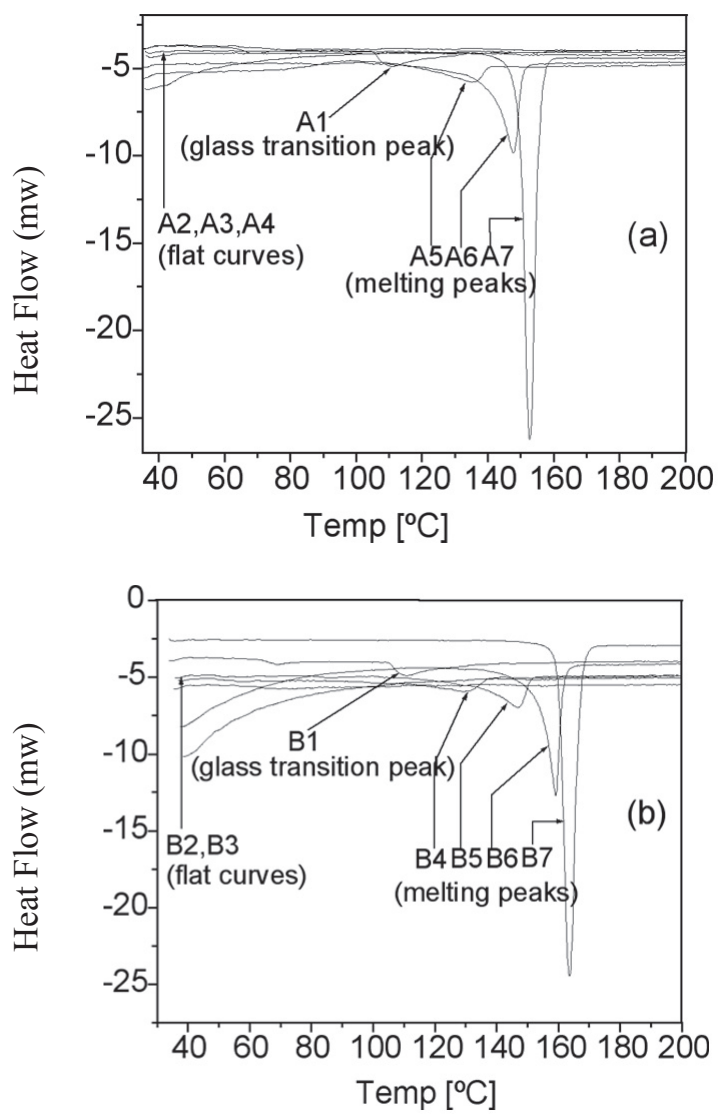

Figure 2. Thermograms of the A1-A7 (a) and B1-B7 (b) series $\left(25-200{ }^{\circ} \mathrm{C}\right.$, $\left.10{ }^{\circ} \mathrm{C} / \mathrm{min}\right)$. 
From the thermograms shown in Figure 2, it is possible to observe another complementary fact. TDP (A7) shows a melting temperature (Tm) of 152.8 ${ }^{\circ} \mathrm{C}$ (supplier reference range $154-156^{\circ} \mathrm{C}$ ), which shifts to lower values as the P(MMA-co-MA) content increases $\left(147.9{ }^{\circ} \mathrm{C}\right.$ and $135.3{ }^{\circ} \mathrm{C}$ for $\mathrm{A} 6$ and $\mathrm{A} 5$ respectively) until it disappears when the blending composition is 50 weight $\%$ in $\mathrm{P}\left(\mathrm{MMA}\right.$-co-MA) (A4). Additionally, the melting molar heats $\left(\Delta \mathrm{H}_{\text {fub }}\right)$ were calculated from the corresponding melting peaks of the thermograms, obtaining 31.9, 13.7 and $3.4 \mathrm{~kJ}$ per mol of TDP for A7 (pure TDP), A6 (20\% P(MMA-coMA)) and A5 (40 \% P(MMA-co-MA)) respectively. Lower energy is required to produce the fusion of TDP as the blend becomes richer in the copolymer. These results might suggest that the crystallinity and the molecular ordering of the TDP component decreases as the P(MMA-co-MA) content increases, due to an intermolecular interaction between both components, until that TDP exists in a amorphous state and its crystallization is completely suppressed in the blends (from A4 to A2). A similar behavior has been described by Inoe et $a l$. for TDP blended with poly( $\varepsilon$-caprolactone) (28). Therefore, in the P(MMAco-MA)/TDP system, it is possible that some kind of interaction, such as hydrogen bonding, should be present between both components. An analogous behavior was observed for the P(MMA-co-MA) / MDP blend. Table 2 presents the corresponding Tm and $\Delta \mathrm{H}_{\text {f }}$ values obtained for both LMWC and their blends with P(MMA-co-MA). The results presented in this Table show that the crystallization of TDP is completely suppressed when the content of P(MMAco-MA) is $50 \%$. When the low molecular weight compound is MDP, the same situation is obtained with a copolymer content of $60 \%$. This fact could be indicative of a larger interaction degree between P(MMA-co-MA) and TDP.

Table 2. Melting temperature (Tm) and melting molar heats $\left(\Delta \mathrm{H}_{\text {fus }}\right)$ for TDP (A7), MDP (B7) and blends with P(MMA-co-MA).

\begin{tabular}{|c|c|c|c|c|c|c|c|}
\hline Blend & \multicolumn{3}{|c|}{ TDP + P(MMA-co- } & \multicolumn{4}{|c|}{ MDP + P(MMA-co-MA) ${ }^{(\mathrm{b})}$} \\
\hline Composition & $\mathrm{A} 7$ & $\mathrm{~A} 6$ & $\mathrm{~A} 5$ & $\mathrm{~B} 7$ & $\mathrm{~B} 6$ & $\mathrm{~B} 5$ & $\mathrm{~B} 4$ \\
\hline$\% \mathrm{P}(\mathrm{MMA}-\mathrm{co}-\mathrm{MA})$ & 0 & 20 & 40 & 0 & 20 & 40 & 50 \\
\hline $\mathrm{Tm}\left({ }^{\circ} \mathrm{C}\right)$ & 152.8 & 147.9 & 135.3 & 163.8 & 159.2 & 146.9 & 129.3 \\
\hline$\Delta \mathrm{H}_{\text {fus }}(\mathrm{kJ} / \mathrm{mol})$ & 31.9 & 13.7 & 3.4 & 29.2 & 17.8 & 7.7 & 3.0 \\
\hline
\end{tabular}

(a): Tm disappears from $50 \%$ in copolymer (A4 composition).

(b): Tm disappears from $60 \%$ in copolymer (B3 composition).

FTIR measurements are a powerful tool to analyze the miscibility in polymer-containing blends. The position changes of the IR absorption peaks resulting from some characteristic functional groups can be attributed to the existence of intermolecular interactions $(4,29,34,39)$. A part of the electronic density of the interacting group is displaced toward the another chemical group, and consequently lower energy is required to produce the corresponding vibration of the chemical bond involved in the interaction. The monomer units of P(MMA-co-MA) contain carbonyl groups (with a significant trend to the hydrogen bonding formation), which absorb at $1733 \mathrm{~cm}^{-1}$ (stretching band). TDP and MDP have no groups that produce absorption in this region. Moreover, they also have chemical groups that can participate in the hydrogen bonding formation (phenol units). Therefore, a shifting of the corresponding stretching band can be related with hydrogen bonding between the blend components. Figure 3 presents the FTIR spectra for the A1-A7 series, and Figure 4 depicts the wave number corresponding to the stretching of $\mathrm{C}=\mathrm{O}$ groups in $\mathrm{P}(\mathrm{MMA}$ co-MA) in the blends with TDP and MDP in relation to the composition. In both cases, a decrease of the wave number is observed, indicating that interactions, like hydrogen bonding, take place between P(MMA-co-MA) and both LMWC, confirming the results obtained by DSC. A larger decrease is observed in the P(MMA-co-MA) / TDP system, which can be understood in terms of the higher polarizability of the S atom of TDP in relation to the methylene carbon atom of MDP (Figure 1). This property increases with the molar mass. In the atoms (and molecules) with higher molecular sizes, some electrons are more distant from the nucleus and, therefore, they move easily and the polarizability increases. Then, the higher polarizability of the $\mathrm{S}$ induced by the polar groups of P(MMA-co-MA) can originate additional dipolar interactions contributing to the P(MMA-co-MA)-TDP miscibility, which was also detected by DSC.

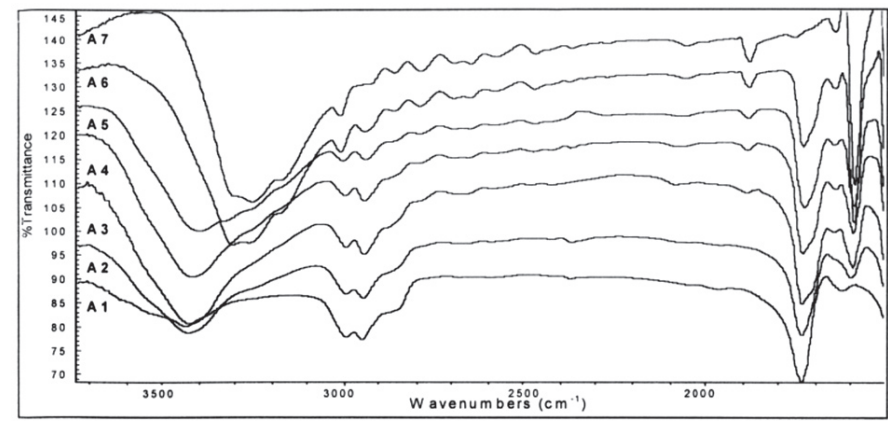

Figure 3. FTIR spectra for P(MMA-co-MA) (A1), TDP (A7), and their blends with TDP contents of $20 \%$ (A2), $40 \%$ (A3), $50 \%$ (A4), $60 \%$ (A5) and 80 $\%$ (A6).

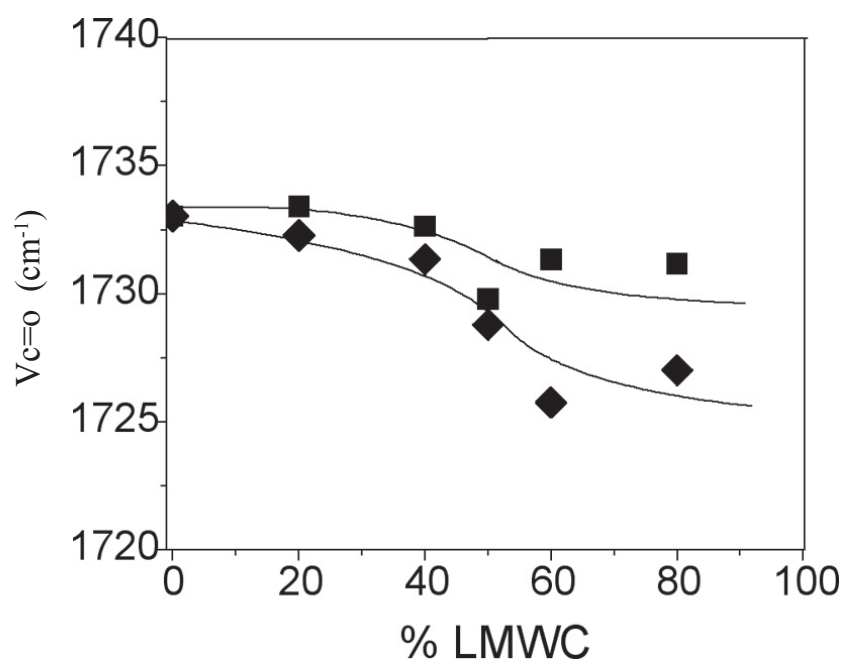

Figure 4. Wave number corresponding to the stretching absorption of $\mathrm{C}=\mathrm{O}$ groups in $\mathrm{P}(\mathrm{MMA}-\mathrm{co}-\mathrm{MA})$ in the blends with $\operatorname{TDP}(\square)$ and $\operatorname{MDP}(\square)$ in relation to the blend composition.

A significant variation in the wave number with the composition, corresponding to the stretching of O-H groups, was also detected. However, even if these chemical groups are directly involved in the hydrogen bonding proposed, the shifts are not useful for identifying the intermolecular interaction because both P(MMA-co-MA) and LMWC have these chemical groups.

Figure 5 shows the thermogravimetric profiles of the blends and the corresponding pure components of the A1-A7 and B1-B7 series. Figure 6 depicts the intrinsic viscosity $([\eta])$ variation with the blend composition for both series. Thermogravimetric (TGA) and viscometry analyses were used as additional techniques to complement the results obtained by FTIR and DSC. Intermediate thermogravimetric profiles of the blends between those corresponding to pure components (as observed in Figure 5) have been reported as evidence for polymer-polymer miscibility $(34,40)$.

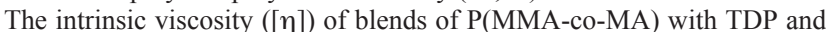
MDP were measured in THF at $298 \mathrm{~K}$. A monotonous diminishing of [ $\eta]$ with the composition is observed in Figure 6 . This is an expected result because as the content of the small molecules increases, the polymer content diminishes. Nevertheless, the decreasing of intrinsic viscosity could be also attributed to a compaction of the polymer chains due to the competition of the LMWC molecules with the solvent ones for the macromolecules as reported for other polymer-LMWC blends (37). Then, the thermogravimetric profiles and the decrease of $[\eta]$ obtained can be considered to be other evidences indicating miscibility. 

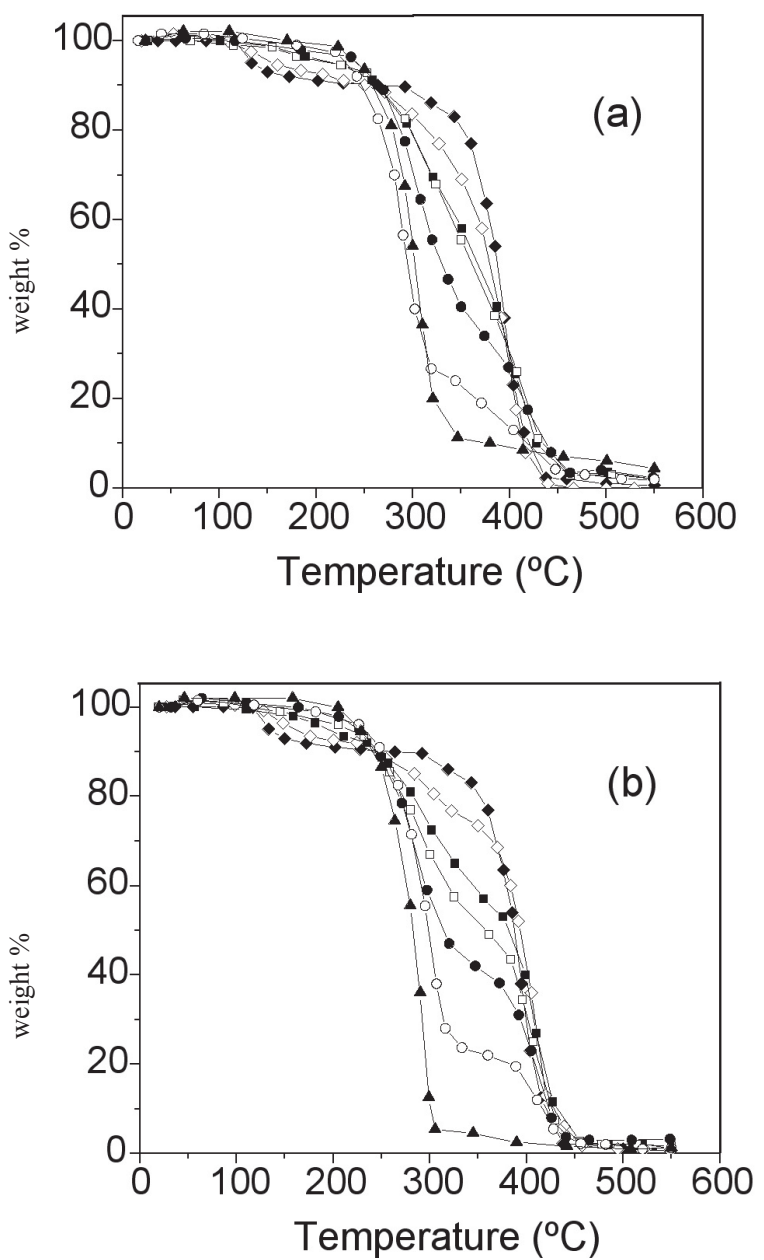

Figure 5. Thermal decomposition profiles of the a) A1-A7 and b) B1-B7

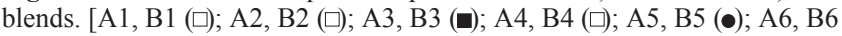
(O) and A7, B7 (४) ]

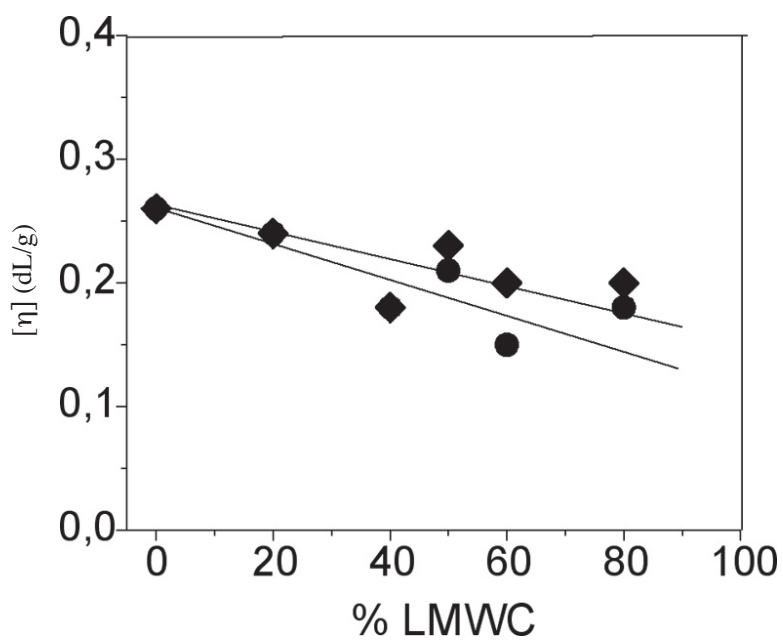

Figure 6. Variation of the intrinsic viscosity $([\eta])$ with the composition for the

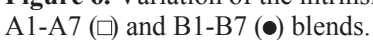

From the decomposition curves of Figure 5, the temperature at which the weight reduction reaches $50 \%\left(\mathrm{~T}_{50}\right)$ were determined for the blends and the pure components of the studied series. $\mathrm{T}_{50}$ is a measure of the decomposition extension for each composed material. In Figure 7 , a decrease of $T_{50}$ with the LMWC content can be observed. The interaction of both TDP and MDP with P(MMA-co-MA) originates a diminishment in the copolymer's thermal stability as the blend becomes richer in the LMWC.

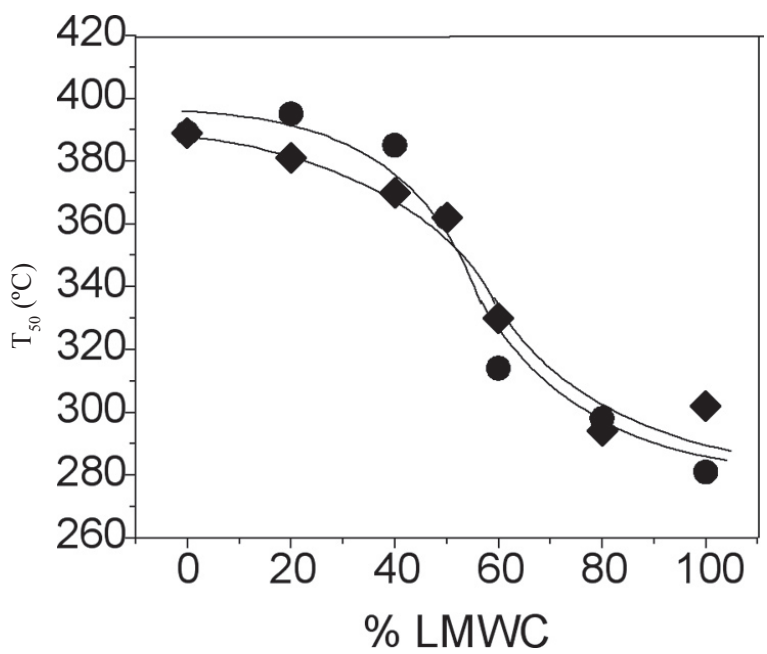

Figure 7. Variation of $\mathrm{T}_{50}$ with the composition for the A1-A7 ( $\square$ ) and B1-B7 (•) blends.

\section{CONCLUSIONS}

P(MMA-co-MA) shows a very clear Tg, which disappears when the copolymer is blended. The addition of the LMWC could be affecting the molecular mobility of the copolymer chains. A shift of Tm for the LMWC is obtained as the P(MMA-co-MA) content increases, until it disappears when the blending composition is 50 and 60 weight $\%$ in copolymer, for the A and B blends respectively, which suggests that the crystallinity of the LMWC decreases as the blend is richer in the copolymer. This result is confirmed by the decrease of the melting molar heat of the LMWC in the same sense. In the carbonyl vibration region of the FTIR spectra, a decreasing of the corresponding wave number is obtained when P(MMA-co-MA) was blended with TDP and MDP for the entire range of blend compositions. The variation in the position of the carbonyl group band can be related with a change of the chemical environment of this group originated by hydrogen bonding. Then, the DSC and FTIR results can be considered as evidence indicating a general miscibility in the studied blends. In agreement with these results, intermediate thermogravimetric profiles of the blends and a monotonous diminishing of $[\eta]$ with the composition were obtained by TGA and viscometry. A decrease in the thermal stability of P(MMA-co-MA) with the LMWC content was also found.

\section{ACKNOWLEDGEMENTS}

We express our thanks to Dirección de Investigación Universidad de Concepción, Grant 203.024.026-1.0, for financial support. 


\section{REFERENCES}

1. "Encyclopedia of Chemical Technology (Kirk-Othmer)", M. Howe-Grant and J I. Kroschwitz, Eds., Vol. 9 p. 559 and Vol. 19 p. 584, John Wiley and Sons Inc., USA, 1998.

2. J. Dong, Y. Ozaki, Macromolecules 30, 286 (1997).

3. S. Kudaibergenov, Z. Nurkeeva, G. Mun, B. Ermukhambetova, A. Akbauova, Macromol. Chem. Phys. 196, 2203 (1995).

4. J. Moore, S.Kaur, Macromolecules 31, 328 (1998)

5. Y. Haiyang, Z. Pingping, R. Feng, W. Yuanyuan, Z. Tiao, Eur. Polym. J. 36, 21 (2000).

6. S. Kuo, W. Huang, C. Huang, S. Chan, F. Chang, Macromolecules 37, 4164 (2004).

7. X. Li, S. Goh, J. Polym. Sci. Polym. Phys. 40, 1125 (2002).

8. M. Geppi, C. Forte, E. Passaglia, B. Mendez, Macromol. Chem. Phys. 199, 1957 (1998).

9. Y. Liu, S. Goh, S. Lee, C. Huan, Macromolecules 32, 1967 (1999).

10. S. Goh, Y. Liu, S. Lee, C. Huan, Macromolecules 32, 8595 (1999).

11. L. Cesteros, E. Meaurio, I. Katime, Macromolecules 26, 2323 (1993).

12. I. Park, J. Barlow, D. Paul, J. Polym. Sci. Polym. Phys. 30, 1021 (1992).

13. K. Zhu, W. Liqun, W. Ji, Y. Shilin, Macromol. Chem. Phys. 195, 1965 (1994).

14. M. Coleman, D. Skrovanek, J. Hu, P. Painter, Macromolecules 21, 59 (1988).

15. J. Kim, M. Whang, C. Kim, Macromolecules 37, 2287 (2004).

16. S. Kuo, S. Chan, H. Wu, F. Chang, Macromolecules 38, 4729 (2005).

17. Y. Miwa, K. Usami, K. Yamamoto, M. Sakaguchi, M. Sakai, S. Shimada, Macromolecules 38, 2355 (2005).

18. J. Zhang, H. Sato, H. Tsuji, I. Noda, Y. Ozaki, Macromolecules 38, 1822 (2005).

19. E. Moon, M. Kim, H. Choi, K. Kim, J. Polym. Sci. Polym. Phys. 40, 1288 (2002).

20. B. Nandan, L. Kandpal, G. Mathur, J. Polym. Sci. Polym. Phys. 40, 1407 (2002).
21. Watanabe, Y. He, N. Asakawa, N. Yoshie, Y. Inoue, Polym. Int. 50, 463 (2001).

22. Y. He, N. Asakawa, Y. Inoue, Macromol. Chem. Phys. 202, 1035 (2001).

23. S. Lakshmi, D. Katti, C. Laurencin, Adv. Drug Deliv. Rev. 55, 467 (2003).

24. G. Tang, K. Zhu, Q. Chen, Drug Deliv. 9, 215 (2002).

25. H. Afrasiabi, F. Sadeghi, A. Ghazi, Drug Dev. Ind. Pharm. 29, 173 (2003).

26. N. Hirasawa, S. Ishise, H. Miyata, K. Danjo, Drug Dev. Ind. Pharm. 29, 339 (2003).

27. J. Liu, Y. Xiao, C. Allen, J. Pharm. Sci. 93, 132 (2004).

28. Y. He, N. Asakawa, Y. Inoue, J. Polym. Sci. Polym. Phys. 38, 1848 (2000).

29. J. Li, Y. He, Y. Inoue, J. Polym. Sci. Polym. Phys. 39, 2108 (2001).

30. H. Cai, J. Brisson, J. Near Infrared Spectrosc. 11, 183 (2003).

31. A. Mujica, M. Calahorra, M. Cortázar, Macromol. Chem. Phys. 203, 1088 (2002).

32. A. González, L. Irusta, M. Fernández-Berridi, M. Iriarte, J. Iruin, Polymer 45, 1477 (2004)

33. A. González, M. Iriarte, P. Iriondo, J. Iruin, Polymer 45, 4139 (2004).

34. D. Radic', N. Gatica, L. Gargallo, Polimery 46, 823 (2001)

35. K. Yamada, H. Yamane, T. Haishi, K. Yamamoto, T. Haraguchi, T. Kajiyama, J. Appl. Polym. Sci. 86, 1113 (2002).

36. H. Huang, S. Goh, D. Lai, C. Huan, Appl. Surf. Sci. 227, 373 (2004).

37. O. Solomon, B. Gotessman, Makromol. Chem. 104, 177 (1967).

38. M. Rocha, Revista de Plásticos Modernos 442, 353 (1993).

39. L. Gargallo, N. Gatica, D. Radic', Intern. J. Polym. Mater. 27, 107 (1994) and references therein.

40. E. Meaurio, J. Velada, L. Cesteros, I. Katime, Macromolecules 29, 4598 (1996). 